\title{
Socio-demographic correlation with Organisational performance among Automobile sales professional of Pakistan
}

\author{
Hassan Mahfooz Rao \\ Sheffield Business School at Sheffield Hallam University \\ Sheffield, United Kingdom \\ Uzma Zaidi \\ College of Health and Rehabilitation Sciences, Department of Health Sciences \\ Princess Nourah Bint Abdulrahman University, Saudi Arabia
}

\begin{abstract}
Keywords
Socio-demographic Variables, Organisational Performance, Automobile Industry, Sales Professionals, Social Factors
\end{abstract}

\begin{abstract}
The purpose of the research paper is to analyse the impact of some socio-demographic variables on the organisational performance. The influence of these socio-demographic variables was evaluated in the context of sales professionals working in the automobile sector of Pakistan.

Conclusive research design has been adopted in the study by using quantitative techniques. Responses were gathered by the sample of 500 sales professionals. The results generated from Pearson correlation, Oneway ANOVA, and descriptive statistics have been used to understand the relationship of socio-demographic variables with organisational performance and to measure the differences between various designations on performance. Responses were tested by conducting statistical tests by using SPSS.

The findings of the study demonstrated that some of the socio-demographic variables have a significant impact on the organisational performance among sales professionals. It was noticed from the correlation that age, education, designation, and income have a strong relationship with organisational performance, whereas, tenure and perceived socio-economic status and incentive has a moderate relationship. Gender, language, and perceived health status were found having no relationship with organisational performance. There was the difference in the performance of sales management and staff members. This depicts the fact that designation influences the working criteria.

In order to improve organisational performance, the socio-demographic variables that must be considered are age, income, education, and designation. The findings demonstrate that there is the no difference in the performance of managers due to their focus, while, the staff members performance differ from each other. This study is providing analysis for the organisations to understand the factors that must be considered in order to improve overall performance.
\end{abstract}

Corresponding author: Hassan Mahfooz Rao

Email addresses for the corresponding author: projectbwp@gmail.com

First submission received: $14^{\text {th }}$ April 2018

Revised submission received: $5^{\text {th }}$ June 2018

Accepted: 3rd August 2018

\section{Introduction}

The automobile industry of Pakistan has witnessed growth in the recent years due to increasing demand among people (Finance Division, Government of Pakistan, 2017). The increase in the demand of the sector has made it essential for the concerned authorities to focus on the aspects that contribute towards organisational performance. Therefore, the purpose of this article is to evaluate the impact of socio-demographic variables on the organisational performance among automobile sales professionals.

This study is focused on evaluating the influence of some of the socio-demographic variables on the performance of the organisation among automobile sales professionals. It will provide specific and relevant information and data about the relationship that will assist organisations in understanding the factors that are important. With the help of this study, the automobile companies in Pakistan would be 
able to comprehend the demographic factors of salespersons that influence the performance of the organisation. It will assist them in the process of evaluating the relationship between some of the demographic variables with organisational performance regarding sales professionals within automobile sector of Pakistan.

It is beneficial to understand the variation of performance within various designation cadres. It can support to identify obstacles of specific designations; potential areas require attention and to plan organisational strategies to enhance organisational performance. Variation within designation further can determine job satisfaction, motivation, retention, performance, and productivity (Latif, Ahmad, Qasim, Mushtaq, Ferdoos \& Naeem, 2013).

\section{Literature Review}

The various point of view available in literature will be covered in this section related to demography and organizational performance. This section will support to formulate hypotheses.

\section{Demography}

According to Bell, Villado, Lukasik, Belau and Briggs (2011), demography can be defined as the research of the overall social status of individuals inside the financial and societal domain. Moreover, it usually comprises different factors that are size, income, job, family, gender, age, education level and job. In addition to this, it involves the investigation of the structure, dissemination of the populations of individuals and size. Furthermore, demographics might also be illustrated as the measurable characteristics of a given populace.

Perryer, Jordan, Firns and Travaglione (2010) stated that demography is the investigation of the populace that comprises disease, death and birth in a particular community. Moreover, it is noted that modern-day demographic research is however not only populace conscious but also has a time aspect. Furthermore, the demographic factors have also been demonstrated by Van Dijk, Van Engen and Van Knippenberg (2012) as the socio-economic features of sales force professionals like experience, education, age, sex, qualification, marital status and other variables. Demographic factors are individual elements that comprise income, educational level, gender, working experience and so on. However, some of the frequently utilised demographic factors as collected from the literature comprises marital status, the location of residence, ethnicity, education, SES, religion, mobility, language, family structure, home and car ownership (Kim \& Agrusa, 2011).

In the current study, demographic factors of sales professionals of Pakistani automobile industry are stated to as their measurable personal features. Moreover, these characteristics entail age, gender, qualification, tenure, average monthly income, socio-economic status, incentives, language, and health status. To address the research question of "What are the demographic variables related to organisational performance among automobile sales professionals of Pakistan?" it was hypothesised that,

H1: Demographic variables (age, gender, qualification, tenure, average monthly income, socioeconomic status, incentives, language and health status) will be positively related to organisational performance among automobile sales professionals of Pakistan.

\section{Organisational Performance}

It is noted that the organisational performance is a frequently used concept in industrial mindset. It mentions how people execute their task to achieve the goals and objectives of the company (Muethel, Gehrlein \& Hoegl, 2012). Organisational performance is the crucial factor because it indicates to the shareholders about the way the company is working. It is basically the measure of actual output against the input or expected output. The organisational performance is improved through the effectual working of the employees. It is the means of determining that whether the organisation has achieved its goals or objectives or not (Bellou, 2010).

Sales professionals in any business field are considered to play significate role to represent their organisation. In respect to the importance of this issue, various studies have tried to highlight buffering or significant variable related to organisational performance. One of the studies has focused the relationship between emotional intelligence and organisational performance among sale professionals, could not find any meaningful relationship (AlDosiry, Alkhadher, Alqaraa \& Anderson, 2015). Some of the efforts have been observed to propose a theoretical framework to study the relationship of organisational performance 
with personality factors and learning (Ma, Yu \& Cheng, 2013). Ma and colleagues (2013) also could not successfully provide an explanation of the relationship of performance with personality or learning. It is essential to study the core factors those could contribute or enhance the performance. To address the research question, "What are the difference in organisational performance between managers and staff members among automobile sales professionals?" it was hypothesised that,

H2: Managers will score higher on organisational performance in comparison to other staff members among automobile professionals.

\section{Methodology}

The methods that are adopted in order to gather information for the article are detailed below:

\section{Research Design}

The study has made use of conclusive research design. It is used in order to generate findings that contribute to making decisions or reaching conclusions. In this type of research studies, the data requirements must be defined explicitly. It provides an opportunity to verify and quantify the findings of the studies. With the help of this research design, the researcher can gather data that are important for generating specific findings and conclusions (Bryman \& Bell, 2015). This research design involves the use of quantitative methods for collecting and analysing data. The purpose of selecting this research design is that it helps in the testing relationship between variables which is the aim of this research study. Moreover, the findings in the conclusive research design are used as input for decision making, which means that the authorities within organisations can make effective decisions for determining the impact of socio-demographic variables on performance (Mackey \& Gass, 2013).

\section{Sample}

Sample was collected from five (5) representative cities of Pakistan as these cities are the focal point for business. Sample size was determined by sample size calculator (Openepi Calculator, nd). The sample size that has been used is 500 participants who are the sales professionals working in the automobile industry of Pakistan (Zikmund, Babin, Carr \& Griffin, 2013; Flick, 2015; Sekaran \& Bougie, 2016). Researcher contacted to the participants and conduct interview or survey in order to generate findings.

\section{Instruments}

The responses received from the participants are maintained in a socio-demographic information sheet. It is measured using perceived organisational performance scale in order to evaluate the extent to which each of the variables influences the organisational performance. The socio-demographic variables that are considered are age, gender, education, tenure, designation, income, perceived socio-economic status, incentives, language, and health status. Organisational performance variables were measured by the standardised scale of organisation performance (Delaney \& Huselid, 1996; Shea, Cooper, Cieri \& Sheehan, 2012).

\section{Data Analysis}

All the information and responses are stored under high encryption so that participants are ensured high maintenance of confidentiality. Moreover, the written informed consent of the respondents is also taken to make sure that their participation is volunteer, and they were not enforced to get involved (Crowther \& Lancaster, 2012). The data gathered in the study was analysed under quantitative data analysis technique which requires the use of statistical tests or techniques in order to generate results (Kumar, 2005). In this research, the findings are generated by conducting statistical tests using SPSS software (v.24). Under it, Person correlation, test for normality, ANOVA, descriptive statistics, and interitem correlation tests were conducted. The tables for each of the test is presented and interpreted in the findings to make sure that the relationship between demographic variables and organisational performance is efficiently understood (Mackey \& Gass, 2013).

\section{Findings}

In this section, the relationship of perceived organisational performance with socio-demographic variables such as age, gender, average monthly income, incentives, socio-economic status, health status, and language is evaluated by performing different tests. 
Table 1 Perceived Organizational Performance reliability assessment

\begin{tabular}{|l|l|c|c|}
\hline Variable & Sub-variables & $\begin{array}{c}\text { Inter-item } \\
\text { Correlation }\end{array}$ & $\begin{array}{c}\text { Cronbach Alpha } \\
\text { a }\end{array}$ \\
\hline $\begin{array}{l}\text { Perceived Organizational } \\
\text { Performance Scale }\end{array}$ & Perceived Organizational Performance & .975 & \multirow{2}{*}{.909} \\
\cline { 2 - 3 } & Perceived Market Performance & .936 & \\
\hline
\end{tabular}

The table 1 showing the inter-item correlation of perceived organisational performance and perceived market performance with perceived organisational performance scale. It is noticed that perceived organisational performance had a score of 0.975 and perceived market performance has a score of 0.936, which means that both are similar and interrelated. Moreover, the Cronbach Alpha value of 0.909 indicates that both variables are highly related to a group.

Table 2 Pearson Correlations Matrix of sociodemographic variables with perceived organizational performance among sales professionals of Pakistan $(\mathrm{N}=500)$

\begin{tabular}{|c|c|c|c|c|c|c|c|c|c|c|c|}
\hline Variables & $(1)$ & $(2)$ & $(3)$ & $(4)$ & $(5)$ & $(6)$ & $(7)$ & $(8)$ & $(9)$ & $(10)$ & $(11)$ \\
\hline$(1)$ & - & & & & & & & & & & \\
\hline$(2)$ & -.005 & - & & & & & & & & & \\
\hline$(3)$ & $.823^{* *}$ & -.023 & - & & & & & & & & \\
\hline$(4)$ & $.284^{* *}$ & .050 & $.433^{* *}$ & - & & & & & & & \\
\hline$(5)$ & $.940^{* *}$ & -.011 & $.883^{* *}$ & $.416^{* *}$ & - & & & & & & \\
\hline$(6)$ & $.940^{* *}$ & -.011 & $.883^{* *}$ & $.416^{* *}$ & $1.00^{* *}$ & - & & & & & \\
\hline$(7)$ & $.400^{* *}$ & .009 & $.529^{* *}$ & $.502^{* *}$ & $.488^{* *}$ & $.488^{* *}$ & - & & & & \\
\hline$(8)$ & $-.685^{* *}$ & .001 & $.601^{* *}$ & $-.439^{* *}$ & $-.688^{* *}$ & $-.688^{* *}$ & $-.457^{* *}$ & - & & & \\
\hline$(9)$ & -.086 & .038 & $-.153^{* *}$ & $-.140^{* *}$ & $-.111^{*}$ & $-.111^{*}$ & $-.111^{*}$ & $.122^{* *}$ & - & & \\
\hline$(10)$ & $-.587^{* *}$ & .024 & $.437^{* *}$ & $-.153^{* *}$ & $-.538^{* *}$ & $-.538^{* *}$ & $-.160^{* *}$ & $.399^{* *}$ & .011 & - & \\
\hline$(11)$ & $.799^{* *}$ & -.016 & $.833^{* *}$ & $.344^{* *}$ & $.830^{* *}$ & $.830^{* *}$ & $.478^{* *}$ & $.594^{* *}$ & -.013 & -.035 & - \\
\hline
\end{tabular}

(1) Age, (2) Gender, (3) Education, (4) Tenure, (5) Designation, (6) Income, (7) Perceived Socio-economic Status, (8) Incentives, (9) Language, (10) Health Status, (11) perceived organizational performance ** $p<.01,{ }^{*} p<.05$

Table 2 indicates the Pearson correlation of the socio-demographic variables with perceived organisational performance among sales professionals of Pakistan. The first variable "Age" is moderately related to perceived organisational performance as it has a correlation value of 0.799 . This means that age has some impact on the performance. However, the second variable "Gender" has a no relationship with performance, indicating that gender does not impact the performance of the sale professionals. This means that no matter the salesperson is male or female the organisational performance would not be influenced by this socio-demographic variable.

The third variable "Education" has a strong relationship with perceived organisational performance as the correlation value is 0.833 . This depicts the fact that the education has an impact on the organisational performance. The education of the sales professionals influences their working in the automobile company due to which overall performance of the organisation is impacted. The highly qualified sales professional seems more likely to be productive and effective for organisational performance. This means that there is a direct relationship between educations of sales professionals with the performance. Moreover, the variable "Tenure" has a very weak relationship with organisational performance because its correlation value is low that is 0.344 . This depicts that tenure that a sales professional has spent in the organisation does not impact the performance.

The fifth variable that is "Designation" has a correlation value of 0.830 which indicates the fact that there is a strong and positive relationship between designation and organisational performance. It means that that the higher the designation of the professional, the more contribution of him or she is towards improved organisational performance. This means that the sales professionals at the higher position are more concerned about the performance of the organisation. In addition to this, the sixth variable "Income" has a correlation value of 0.830 which means that it has a strong relationship with organisational performance. This is because income has a direct association with the performance of the employees are it motivates or demotivates them to work. This means that the higher the income of the sales professional, the more effectively they will work due to which organisation performance would improve.

www.jbrmr.com A Journal of the Academy of Business and Retail Management (ABRM) 
The variable "perceived socio-economic status" is moderately related to organisational performance as there is a correlation value of 0.478 . It is noticed that the socio-economic status does not impact the working criteria for the employees. Whether the sales professional is from upper, middle, or low class, it does not matter because it has a minor impact on the performance of the organisation. Furthermore, the eighth variable of "Incentives" have a moderate relationship with organisational performance as it has a significant correlation value of 0.594. Based on this, it is noticed that the incentives impact the organisational performance. This means that if the sales professionals are given incentives, it will influence the performance of the organisation. In addition to this, the last two variables "Language" and "Perceived Health Status" have no relationship with the "Organisational Performance". This depicts the fact that language and perceived health status of the sales professionals do not contribute to improving the performance of the organisation.

Table 3 Test of Normality for Performance

\begin{tabular}{|l|c|c|c|c|c|c|}
\hline & \multicolumn{2}{|l|}{ K-S with Lilliefors Correction Test } & \multicolumn{2}{|l|}{ Shapiro-Wilk Test } \\
\cline { 2 - 7 } & Statistic & Df & P-value & Statistic & $\mathrm{df}$ & $P$-value \\
\hline Organizational Performance & .311 & 500 & .072 & .790 & 500 & .063 \\
\hline
\end{tabular}

Table 3 is showing the result of the test of normality conducted for evaluating organisational performance in the automobile sector of Pakistan. It is noticed that the significance value of the organisational performance under both K-S with Lilliefors test and Shapiro-Wilk test is higher than 0.05, which means that there is the difference in the performance of sales professionals. It indicates that there is the impact of various factors on the organisational performance which must be considered in order to improve the functioning.

Table 4 One-way ANOVA of Performance by Managers and Staff members ( $N=500)$

\begin{tabular}{|l|l|l|l|l|l|}
\hline Source & Ss & $d f$ & MS & F & p \\
\hline Between Groups & 10630.793 & 5 & 2126.159 & 335.535 & .000 \\
\hline Within Groups & 3130.295 & 494 & 6.337 & & \\
\hline Total & 13761.088 & 499 & & & \\
\hline
\end{tabular}

${ }^{* *} \mathrm{p}<0.01$

The table 4 is indicating the result of one-way ANOVA of performance by staff members and managers. It is noticed that the value of $p$ is 0.000 which is lower than 0.05 . This indicates that there is a statistically significant relationship between the two variables. It is noticed that there is the statistically significant difference in the performance of managers and staff members. This means that the managers have different contribution towards the performance of the organisation as compared to staff members.

Table 5 Descriptive Statistic for Organisational performance among Managers and Staff members

\begin{tabular}{|l|c|c|c|c|}
\hline Organisational performance & $N$ & $M$ & $S D$ & Std. Error \\
\hline Sale Executive & 177 & 28.90 & .751 & .056 \\
\hline Senior Sales Executive & 98 & 28.99 & .696 & .070 \\
\hline Assistant Manager & 83 & 33.98 & 4.297 & .472 \\
\hline Manager & 67 & 38.94 & 3.223 & .394 \\
\hline Deputy General Manager & 41 & 40.46 & 2.684 & .419 \\
\hline General Manager Sales and Marketing & 34 & 39.38 & 3.877 & .665 \\
\hline Total & 500 & 32.77 & 5.251 & .235 \\
\hline
\end{tabular}

Table 5 is the presentation of descriptive statistics for organisational performance among managers and staff members. It is noticed that standard deviation of the staff members is lower than those of managers. The sale executive and senior sales executive have a standard deviation of 0.751 and 0.696 ,

www.jbrmr.com A Journal of the Academy of Business and Retail Management (ABRM) 
which indicates the fact that the information shared by them is not widespread and are close to the mean. This means that the responses of the staff members are closely related to each other and there is not high deviation within their response. While on the other hand, the standard deviation of the managers is very high which means that there is difference in the responses of the people at different managerial position, for instance, the general manager sales and marketing has standard deviation of 3.877 and assistant manager has 4.297 which means that the response of both was widely different from each other as the data is widespread.

Table 6 Multiple Comparisons of Organizational Performance among Managers and Staff members

\begin{tabular}{|c|c|c|c|c|}
\hline (I) Designation & (J)Designation & $\begin{array}{c}\text { Mean Difference } \\
(\mathrm{I}-\mathrm{J})\end{array}$ & Std. Error & Sig. \\
\hline \multirow{5}{*}{ Sale Executive } & Senior Sales Executive & -.086 & .317 & 1.000 \\
\hline & Assistant Manager & $-5.072^{*}$ & .335 & .000 \\
\hline & Manager & $-10.036^{*}$ & .361 & .000 \\
\hline & Deputy General Manager & $-11.559^{*}$ & .436 & .000 \\
\hline & General Manager Sales and Marketing & $-10.478^{*}$ & .471 & .000 \\
\hline \multirow{5}{*}{$\begin{array}{l}\text { Senior Sales } \\
\text { Executive }\end{array}$} & Sale Executive & .086 & .317 & 1.000 \\
\hline & Assistant Manager & $-4.986^{*}$ & .376 & .000 \\
\hline & Manager & $-9.951^{*}$ & .399 & .000 \\
\hline & Deputy General Manager & $-11.474^{*}$ & .468 & .000 \\
\hline & General Manager Sales and Marketing & $-10.393^{*}$ & .501 & .000 \\
\hline \multirow{5}{*}{$\begin{array}{l}\text { Assistant } \\
\text { Manager }\end{array}$} & Sale Executive & $5.072^{*}$ & .335 & .000 \\
\hline & Senior Sales Executive & $4.986^{*}$ & .376 & .000 \\
\hline & Manager & $-4.964^{*}$ & .413 & .000 \\
\hline & Deputy General Manager & $-6.488^{*}$ & .481 & .000 \\
\hline & General Manager Sales and Marketing & $-5.406^{*}$ & .513 & .000 \\
\hline \multirow{5}{*}{ Manager } & Sale Executive & $10.036^{*}$ & .361 & .000 \\
\hline & Senior Sales Executive & $9.951^{*}$ & .399 & .000 \\
\hline & Assistant Manager & $4.964^{*}$ & .413 & .000 \\
\hline & Deputy General Manager & -1.523 & .499 & .099 \\
\hline & General Manager Sales and Marketing & -.442 & .530 & .983 \\
\hline \multirow{5}{*}{$\begin{array}{l}\text { Deputy General } \\
\text { Manager }\end{array}$} & Sale Executive & $11.559^{*}$ & .436 & .000 \\
\hline & Senior Sales Executive & $11.474^{*}$ & .468 & .000 \\
\hline & Assistant Manager & $6.488^{*}$ & .481 & .000 \\
\hline & Manager & 1.523 & .499 & .099 \\
\hline & General Manager Sales and Marketing & 1.081 & .584 & .635 \\
\hline \multirow{5}{*}{$\begin{array}{l}\text { General } \\
\text { Manager Sales } \\
\text { and Marketing }\end{array}$} & Sale Executive & $10.478^{*}$ & .471 & .000 \\
\hline & Senior Sales Executive & $10.393^{*}$ & .501 & .000 \\
\hline & Assistant Manager & $5.406^{*}$ & .513 & .000 \\
\hline & Manager & .442 & .530 & .983 \\
\hline & Deputy General Manager & -1.081 & .584 & .635 \\
\hline
\end{tabular}

The tables above show the statistical result of the responses received from managers and staff members of the automobile organisations. Table 6 is giving the multiple comparisons of the performance of managers and staff members. It is noticed that sales executive has a statistically significant difference in performance with all the staff members except senior sales executive because the significance value is 1 . Similarly, the senior sales executive has a statistically significant relationship with all the employees 
except sales executive. Moreover, assistance manager has a statistically significant difference with all the members as the value is less than 0.05. This means that there is the difference in the performance of the staff members who are working under an assistant manager. Furthermore, the manager has a statistically significant relationship with the sales executive, senior sales executive, and assistant manager, while, it has a statistically insignificant relationship with general manager sales and marketing and deputy general manager. Apart from this, deputy general manager and general managers sales and marketing have a statistically insignificant relationship with the manager and deputy general manager as the significant value is higher than 0.05 . This means that there is no significant difference in the performance of a manager, general manager sales and marketing, and deputy general manager.

Table 7 Homogenous subsets of Organizational Performance by Scheffe test

\begin{tabular}{|l|c|l|l|l|l|}
\hline Designation & $\mathrm{N}$ & \multicolumn{5}{|c|}{ Subset for alpha $=0.05$} \\
\hline & & 1 & 2 & 3 & 4 \\
\hline Sale Executive & 177 & 28.90 & & & \\
\hline Senior Sales Executive & 98 & 28.99 & & & \\
\hline Assistant Manager & 83 & & 33.98 & & \\
\hline Manager & 67 & & & 38.94 & \\
\hline General Manager Sales and Marketing & 34 & & & 39.38 & 39.38 \\
\hline Deputy General Manager & 41 & & & & 40.46 \\
\hline Sig. & & 1.000 & 1.000 & .966 & .335 \\
\hline
\end{tabular}

The table 7 shows that the group of Sales executive and Senior sales executive have not significantly different for organisational performance. Moreover, Manager and General manager, and General Manager and Deputy General Manager also have no significate difference. The only group not overlapping and are significantly different is the group of Assistant Managers.

\section{Discussion and Conclusion Discussion}

It is analysed from the above findings that some demographic factors impact the organisational performance positively. Moreover, these demographic factors include age, education, designation, and income. In addition to this, it is noted that the educated employees are quite encouraged towards the attainment of organisational goals and targets in a consistent manner (Muethel et al., 2012). Therefore, the top officials of the automobile industry of Pakistan prefer those employees that are educated because they contribute massively to the better organisational performance. Furthermore, it is found that the employees on top designation play an imperative part in the organisational performance. However, from the findings, it is evaluated that income is one of the essential sociodemographic factors which has a substantial impact on organisational performance. Due to the intense competition in the automobile sector, the policy makers of firms consider this factor to facilitate the employees' particularly sales personnel to perform their part in a more effective manner (Bell et al., 2011).

It is examined from the above-mentioned findings that few socio-demographic factors have no impact on the organisational performance including gender, language and perceived health (Bell et al., 2011). Although these findings are not consistent with previous studies but can be explained with respect to current data and recent studies. In sales and marketing sector of Pakistan involvement of female are minimal (Bibi, 2016). In the current study, approximately only 20 female sales professionals responded. As far as language is concerned, no previous study has reported relationship of language and organisational performance in Pakistan. In the current study, there were three options as a regional language, National, and International language. Most of the sales professionals were found using National language for interaction and conversation at the workplace. Only Managerial staff were found using International language at official meetings. But while the conversation with another staff member they reported to use National language. Thus, the mixed language use might facilitate or do not impact upon performance. For this reason, it is important from the prospect of automobile firm's officials do not ponder too much about these factors while formulating plans and strategies related to sales personnel.

On the other hand, there are some socio-demographic factors that impact the organisational performance to some extent and these factors entails incentives and socio-economic status. It is noted that 
most of the organisations particularly automobile firms consider these factors in order to improve the organisational performance effectively (Muethel et al., 2012). Therefore, they formulate effective employee motivation plan that includes different incentives for workers which help them to encourage their sales personnel to contribute their part in the success of a business. Furthermore, the role of sales personnel is crucial in the automobile industry because they are responsible for pursuing client to purchase a product without any apprehension. For that reason, it is vital for the enduring success of Pakistani automobile industry that they should provide all kind of possible support to their employees which help them to enhance organisational performance viably (Van Dijk et al., 2012).

The findings have determined the fact that the performance of the sales professionals also varies regarding their designation. It has been noticed that the performance of the sales professionals at the managerial position is not very different. However, the performance of the staff members differs from each other. This depicts the fact that the designation has a significant impact on the organisational performance. The professionals at the managerial positions are more focused, and their objective is similar due to which there is little difference in their performance. While on the other hand, the staff members have diverse aims and directions due to which there is the difference in their performance. Furthermore, the demographic variables have an impact on the organisational performance in the manner that the sales professionals with good educational background and high income would contribute more towards the achievement of goals and objectives than the professionals that have low income. In addition to this, the age variable impacts their performance in the manner that young sales employees would bring some innovative and new technique which will influence the performance of the organisation effectively. However, the old employees would not be able to bring innovation to the organisation due to which performance would be impacted. Therefore, based on the findings, it has been analysed that these variables can impact the performance of the organisation either negatively or positively.

\section{Conclusion}

The purpose of the article was to evaluate the relationship of socio-demographic factors with organisational performance among sales professionals of the automobile industry of Pakistan. The variables that are considered in this paper are age, gender, education, tenure, designation, income, perceived socio-economic status, language, incentives, and health status. The impact of these variables on the performance of organisation among sales professionals of the automobile industry of Pakistan is evaluated. This research study is designed with the intention to assist organisations in understanding the way these variables can impact their performance and the importance they hold with respect to sales professionals. With the help of this study, the management of an organisation can determine the sociodemographic variables that are significant for them and can influence the business performance. In order to evaluate the relationship of socio-demographic variables with organisational performance among automobile sales professional of Pakistan, the quantitative data analysis is used as the technique. Different statistical tests have been conducted to generate reliable findings and to determine the relationship of each variable with organisational performance.

The findings of the study demonstrate that there are some of the variables that have a strong relationship with organisational performance. The variables that are strongly correlated with performance are age, education, designation, and income. It is noticed that each of these variables have a high correlation which indicates that these socio-demographic factors impact the performance. Moreover, the performance is also evaluated in terms of the designations of the sales professionals. The results indicate that there is no statistical difference among the performance of the professionals at the designation of managers such as manager, general manager sales and marketing, and deputy general manager. However, there is the difference in the performance of staff members which means that the assistant managers are focused towards a single direction, but staff members differ. Based on the findings and discussion, it has been concluded that four of the socio-demographic variables are correlated with organisational performance. These variables impact the performance of sales professionals which has a direct influence on the organisational performance. 


\section{Research Limitations and Directions for Future Research Research Limitations}

There are few limitations in this research that must be considered by the researcher at the time of conducting the research. The first limitation that has impacted this research study is the availability of secondary data. It is noticed that no much secondary data was available on the selected topic due to which it became difficult to determine the flow of the research. In addition, limited availability of study made it difficult to comprehend the structure that must be followed to evaluate the correlation of sociodemographic variables with organisational performance. Moreover, another limitation of this study is that it has focused on only one department that is Sales. This means that the impact of socio-demographic factors on the organisational performance is evaluated in the context of only sales professionals due to which the scope of the study is made limited.

\section{Directions for Future Research}

There are some necessary directions for future research that ought to be considered by an investigator to enhance the effectiveness of research to the utmost level. However, some necessary directions for future research are mentioned here. It is crucial for research that the researcher should use both primary and secondary data because rely on a single type of information might impact the reliability of research. Research should consider all sorts of information rather than focus on any single kind of data. Future research can include various department of automobile sector to enhance the scope.

\section{References}

AlDosiry, K. S., Alkhadher, O. H., Alqaraa, E. M. and Anderson, N. (2015). Relationships between emotional intelligence and sales performance in Kuwait. Journal of Work and Organizational Psychology, 32(1), pp. 39-45.

Bellou, V. (2010). Organizational culture as a predictor of job satisfaction: the role of gender and age. Career Development International, 15(1), pp.4-19.

Bell, S.T., Villado, A. J. Lukasik, M. A., Belau, L. and Briggs, A. L. (2011). Getting specific about demographic diversity variable and team performance relationships: A meta-analysis. Journal of management, 37(3), pp.70943.

Bibi, N. (2016). Role of Gender Diversity in Organizational Effectiveness and its Implications. International Review of Management and Marketing, 6(S4), pp.80-85.

Bryman, A. and Bell, E. (2015). Business Research Methods. London: Oxford University Press.

Crowther, D. and Lancaster, G., (2012). Research Methods. Jordan Hill: Routledge.

Flick, U. (2015). Introducing research methodology: A beginner's guide to doing a research project. England: Sage.

Delaney, J. T and Huselid, M. A. (1996). The impact of human resource management practices on perceptions of organizational performance. Academy of Management Journal, 39 (4), 949-969.

Kim, H. J. and Agrusa, J. (2011). Hospitality service employees' coping styles: the role of emotional intelligence, two basic personality traits, and socio-demographic factors. International Journal of Hospitality Management, 30(3), pp.588-98.

Kumar, R. (2005). Research Methodology: a step-by-step guide for beginners. 2nd ed. Thousand Oaks: Sage Publications Ltd.

Kunze, F., Boehm, S. A. and Bruch, H. (2011). Age diversity, age discrimination climate and performance consequences - a cross organizational study. Journal of organizational behavior, 32(2), pp.264-290.

Latif, M. S., Ahmad, M., Qasim, M., Mushtaq, M., Ferdoos, A. and Naeem, H. (2013). Impact of employee's job satisfaction on organizational performance. European Journal of Business and Management, 5(5), pp. 166-171.

Ma, C-M., Yu, C-T. and Cheng, B-W. (2013). An Integrative Framework among Automobile Salespeople Personality, Learning and Sales Performance. Journal of Applied Sciences, 13 (8), 1177-1184.

Mackey, A. and Gass, S.M., (2013). Second language research: Methodology and design. London: Routledge.

Muethel, M., Gehrlein, S. and Hoegl, M. (2012). Socio-demographic factors and shared leadership behaviors in dispersed teams: Implications for human resource management. Human Resource Management, 51(4), pp.525-48.

Finance Division, Government of Pakistan (2018). Overview of economy. Pakistan economic survey 2017-2018. Available at: http:/ / www.finance.gov.pk [Accessed 01 Jun. 2018]

Openepi (n.d). Sample size calculator [A web-based statistical calculator for sample size] Available at: http://www.openepi.com [Accessed 24 Jan. 2017].

Park, T.Y. and Shaw, J.D. (2013). Turnover rates and organizational performance: A meta-analysis. Journal of applied psychology, 98(2), p.268. 
Perryer, C., Jordan, C., Firns, I. and Travaglione, A. (2010). Predicting turnover intentions: The interactive effects of organizational commitment and perceived organizational support. Management Research Review, 33(9), pp.91123.

Sekaran, U. and Bougie, R. (2016). Research methods for business: A skill building approach. London: John Wiley \& Sons.

Shea, T., Cooper, B. K., Cieri, H. D. and Sheehan, C. (2012). Evaluation of a perceived Organisational performance scale using Rasch model analysis. Australian Journal of Management, 37 (3), p. 507-522

Thatcher, S. and Patel, P.C. (2011). Demographic faultlines: A meta-analysis of the literature. Journal of Applied Psychology, 96(6), p.1119.

Van Dijk, H., Van Engen, M.L. and Van Knippenberg, D. (2012). Defying conventional wisdom: A meta-analytical examination of the differences between demographic and job-related diversity relationships with performance. Organizational Behavior and Human Decision Processes, 119(1), pp.38-53.

Zikmund, W.G., Babin, B.J., Carr, J.C. and Griffin, M. (2013). Business research methods. England: Cengage Learning. 